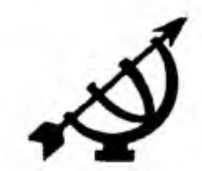

\title{
Versoening en moontlike versoeningsimbole in die hedendaagse Suid-Afrika
}

\author{
George A. Lotter \\ Skool vir Kerkwetenskappe \\ Potchefstroomse Universiteit vir $\mathrm{CHO}$ \\ POTCHEFSTROOM \\ E-pos: kwsgal@puknet.puk.ac.za \\ Abstract \\ Reconciliation and possible symbols of reconciliation in contemporary South \\ Africa \\ In this article the important issue of reconciliation is addressed, and certain \\ dimensions of reconciliation are discussed: perspectives from Scripture, \\ forgiveness as prerequisite; restitution as a result and the process itself \\ The important role of the church of Jesus Christ as initiator and facilitator of \\ the process of reconciliation is also stressed. The article ends with a \\ statement that the time has come for new symbols of reconciliation in \\ South Africa and some ideas for reconciliatory gestures are proposed.
}

\section{Inleiding}

Midde in ' $n$ nuwe millennium is die saak van versoening in Suid-Afrika, maar ook wêreldwyd, (nog steeds) aktueel en behoort dit prinsipieel ook die nodige aandag te kry. ${ }^{1}$ Ook is daar reeds aanduidings van vorme van versoening wat plaasvind (Krog, 1998:111; Meiring, 1999:71; TRC, 5:392; Tutu, 1999:117). Vanuit die teologie behoort ook duidelike riglyne gegee te word oor versoening en nie net op die terrein van die ekonomiese, morele, en psigologiese aspekte nie (Smit, 1992:56; König, 1995:114-122; Van Wyk, 1999:216). Meiring (1999:387) stel dit ook duidelik dat veral Christene in Suid-Afrika versoening moet nastreef en inisieer. Die gevaar bestaan steeds dat riglyne vir versoening vanuit die

1 Vgl. onder andere Hofmeyr, 1992:106; Brummer, 1994:42: Van Houten, 1998:3; De Klerk, 1999:24; Lotter, 1999:2, Kruger, 1999:24, Villa-Vicencio, 1999:53 en Du Toit, 1999:7 
skepping gekonstrueer word in plaas vanuit die herskepping (soos gebeur het met apartheid) (Smit, 1996:125, 126); wat beteken dat die wêreld riglyne neerlê van hoe versoening behoort te geskied en nie die kerk (op grond van die Woord) nie.

Die term versoening het egter mettertyd afgeslyt geraak (Gunton, 1989: 177) en beteken vir verskillende mense verskillende dinge. Krog byvoorbeeld (1998:109-113) toon ook aan hoe verskillende soorte versoening moontlik kan bestaan, en watter verwarring kan voorkom oor wat versoening eintlik beteken.

In hierdie artikel sal aangetoon word dat 'n geldige begrip van Bybelse versoening belangrik en noodsaaklik is en dat dit deurgetrek moet word na versoening tussen mense onderling in die Suid-Afrikaanse konteks (vgl. Meiring, 1999:386). Sake wat ook ten nouste met versoening te doen het, soos vergewing (Lotter, 1996:2) en restitusie (Walker, 1994:49) sal ook kortliks aan die bod kom, waarna die proses van versoening kortliks bespreek word. Daar sal verder aangetoon word dat die kerk van Jesus Christus 'n besondere verantwoordelikheid het om versoening te fasiliteer.

Ten slotte word sekere godsdienstige, praktiese en emosionele simbole voorgestel wat versoening enersyds uitdruk en andersyds bevorder. "Simbole" sal dui op sake, plekke, dinge en rituele wat 'n teken kan wees van iets anders en méér as dit waarvoor dit staan en waarna dit verwys. Die uiterlik waarneembare saak (bv. monument, boek of ritueel) verwys na iets baie groter en dieper as sigself, maar stimuleer mense tog saam om daardie dieper saak te dien.

\section{Dimensies van versoening}

\subsection{Skrifperspektiewe op versoening}

Turaki (1993:24 - 27) gee 'n kort, maar kernagtige uiteensetting van die drie fasette van versoening:

- tussen God en mens op grond van die verlossingswerk van Jesus Christus aan die kruis (vgl. onder andere Rom. 5:8-1 en 2 Kor. 5:1821);

- tussen mense onderling wat vroeër vyande was (Gal. 3:28; Ef. 2:1122) en

- versoening van die gevalle natuur in die kruis van Jesus Christus (Kol. 1:19-22; 2 Kor. 5:19; Rom. 8:18-22). Alle versoening spruit egter uit die belangrikste versoeningsdaad van God in Jesus Christus - in die 
woorde van Rabali (1987:58) - we were reconciled to God by the redemptive acts that necessitated the dying on the cross of Jesus Christ to resolve the problem of $\sin "$

- Van Houten (1998:7) wys op die belangrike feit dat God eerste opgetree het in die versoening van die mens met Homself in Jesus Christus. God neem die inisiatief op grond van sy verbond met die mens en herstel die verhouding om deur versoening "die vervreemding uit die weg te ruim" (König, 1995:7). 'n Verdere aspek van versoening word duidelik deur Louw \& Nida (1988, 1:502, vgl. voetnoot 1) na vore gebring: "Meanings involving reconciliation have a presuppositional component of opposition and hostility, and it is the process of reconcialtion which reverses this presuppositional factor" (kursivering deur die skrywer). Dit is amper asof die Suid-Afrikaanse situasie beskryf word waarvoor versoening nodig is!

Versoening impliseer dus in die eerste plek versoening met God. Dit word egter baie duidelik dat daardie tipe versoening in die teologie en kerklike kringe dikwels die nodige aandag gekry het, maar dat die beginsel van versoening van mense onderling, nie altyd so skerp deurgetrek is nie (Venter, 1991:213). Hierdie faset (naamlik die ontbreking/verswyging van versoening tussen mense) was waarskynlik een van die grootste leemtes in die Suid-Afrikaanse konteks (vgl. Maswanganyi, 1992:19-22) en het onder andere veroorsaak dat die invloed van die evangelie verminder is, omdat mense nie uitgeleef en toegepas het wat prinsipieel geglo is nie. Dit lyk egter of daar weer opnuut en anders gekyk word na wat versoening inderdaad binne die konteks van Suid-Afrika beteken. Verblydende tekens is byvoorbeeld die uitspraak van die Gereformeerde Konvent (vgl. Krüger, 1999:24):

Die Konvent het sy deelnemende kerk opgeroep om 'n leidende rol te speel in die versoening van mense en groepe met mekaar deur die verkondiging en bediening van die versoening in Christus (kursivering deur die outeur).

Volgens Lotter (1996:7-10) is Bybelse vergewing nodig op mikrovlak (mens-tot-mens); mesovlak (tussen bv. volke) en makrovlak (bv. verdrukte-tot-onderdrukte). Dieselfde Bybelse kriteria kan toegepas word vir versoening as die volgende stap in die proses van vergewing (vgl. 2.4 hieronder): versoening behoort ook op mikro-, meso- en makrovlak nagestreef te word as antwoord op die Bybelse eis (vgl. byvoorbeeld Galasiërs 3:26 - 28). 


\subsection{Vergewing as voorwaarde tot versoening}

Daar bestaan ' $n$ besonder nou verband tussen versoening en vergewing omdat vergewing eers moet plaasvind voordat versoening moontlik word (Sande, 1991:170; Krishna, 1993:7; De Klerk, 1999:29). Soos Lotter (1996:2) dit stel: "Forgiveness clears the way for reconciliation, for in forgiveness the stumbling block in the way of reconciliation is removed."

Ook die Kairos-dokument wat in die tagtigerjare groot opslae gemaak het, verbind versoening en vergewing sterk met mekaar (Kairos Document, 1985:18):

The Biblical teaching on reconciliation and forgiveness makes it quite clear that nobody can be forgiven and reconciled with God unless he or she repents of their sins. Nor are we expected to forgive the unrepentant sinners. When he or she repents, we must be willing to forgive seventy times seven but before that, we are expected to preach repentance to those who sin against us or against anyone (kursivering deur die skrywer).

Cloete en Smit (1984:12) skryf in die begeleidende brief by die Belharbelydenis dat hulle pleit om "die egte versoening wat volg op bekering en verandering van gesindhede ..." (kursivering deur die skrywer). Alhoewel vergewing nie by die naam genoem word nie, is dit geimpliseer en dui dit ook op die chronologie wat bestaan tussen vergewing en versoening.

Die proses van vergelyking kan grafies soos volg voorgestel word (Lotter, 1987:38):

$$
\begin{aligned}
& \text { Sondaar } \\
& \text { Persoon teen wie gesondig word } \\
& \text { Vra vergewing } \\
& \text { Sondaar <---orsoon teen wie gesondig is } \\
& \text { Verleen vergewing }
\end{aligned}
$$

Die hele proses is eers volledig afgehandel as dit soos volg daar uitsien:

$$
\text { Sondaar <--a---orsoon teen wie gesondig is }
$$

\subsection{Restitusie as gevolg van versoening}

Restitusie is ' $n$ besondere emosionele saak wat nie van versoening losgemaak kan word nie (vgl. Van Wyk, 1999:218). Meiring (1999:387) maak ' $n$ sterk stelling in diè verband: "Jy kan byvoorbeeld nie van versoening praat sonder om in dieselfde asem oor geregtigheid, verantwoordelikheid en restitusie te praat nie" (kursivering deur die 
skrywer). Op Skriftuurlike gronde kry restitusie ook aandag: in die Ou Testament is daar verwysings na die Hersteljaar en die Jubeljaar wat in Levitikus 25 en Numeri 36 beskryf word (Helberg, 1990:64), terwyl die ruim teruggawe van onregmatige skade (volgens die Romeinse gebruik: viervoudig) in Lukas 19:8 genoem word (De Klerk, 1999:32). Restitusie behels nie alleen sake soos die herstel van grondregte en die teruggee van grond nie, maar kom byvoorbeeld ook ter sprake by regstellende aksie (Smit, 1992:32) en die herstel van verhoudinge na skuldbelydenis (Potgieter, 1991:100). De Klerk (1999:31) verwys tereg na die weerstand wat ondervind word by versoening as daar nie ook restitusie is nie. Omdat versoening in die Suid-Afrikaanse konteks so 'n omvattende saak is, beskou sekere skrywers die relevansie van restitusie net so omvattend. Summers (1992:26) wil byvoorbeeld die aandag rig op die onderwys en sy rol in die versoeningsproses:

It is important that pupils are taught that working for reconciliation is a costly undertaking because it means not only striving for justice but also making restitution whenever and wherever possible.

Dit is ' $n$ faset wat waarskynlik nog nie genoeg beklemtoon is in sowel die tradisionele wit as die swart skole in Suid-Afrika nie.

Helberg $(1990: 64,135)$ gee 'n goeie prinsipiële uiteensetting van die hele saak van grond- en grondbesit. Alhoewel dit duidelik is dat mense vir God belangriker as grond is en dat God Hom nie bind aan grond nie, is restitusie as onderdeel van versoening in die huidige Suid-Afrikaanse konteks besonder brandend. In die soeke na riglyne ten opsigte van restitusie ("restoration"), is die riglyne van Van Houten (1998:16-17) besonder nuttig en bruikbaar en kan waarskynlik in Suid-Afrika as uitgangspunt geneem word:

- In restitusie kan die skade nooit volledig herstel word nie.

- Die onderdrukker behoort vrygewig te wees (vgl. Saggeus se optrede volgens Lukas 19:1-10).

- Restitusie is nie "terugbetaling" nie omdat vergelding nie deel van versoening behoort te wees nie.

- Daar moet wedersydse ooreenstemming wees oor die proses tussen die onderdrukker en die slagoffer.

Dit is duidelik dat die laaste woord oor restitusie nog lank nie gespreek is nie en daarom sal veral prinsipiële denke daaroor baie meer aandag moet geniet. In die woorde van Lotter (1996:13):

There is a dire need for studies of this kind in explaining the Biblical foundations of forgiveness, reconciliation and restitution. The latter is 
Versoening en moontlike versoeningsimbole in die hedendaagse Suid-Afrika

especially a minefield of opposing ideas on what restitution really means! (Kursivering deur die skrywer.)

\subsection{Die proses van versoening}

Versoening kan nie net ' $n$ Bybelse beginsel bly nie, maar moet ook toegepas en uitgeleef word.

Soos vroeër aangetoon (vgl. Venter, 1991:213), het die ware Christelike versoening nie altyd grondgevat in die verhouding met mense onderling nie. Volgens Van Wyk (1991:179) is kerke dikwels geneig om groter klem op die leer (ortodoksie) as op die lewe (ortopraksie) te plaas. König (1995:72) gee 'n treffende, dog ontstellende voorbeeld van hoe hierdie versoening tussen God en mens nie deurgewerk het na ander mense toe nie:

'n Mens moet jou indink hoe slawehandelaars byvoorbeeld met geweld 'n klomp mense iewers in Afrika gevang het, hulle vasgebind het en hardhandig in skeepsruime ingelaai het. Nogtans het hulle tydens die reis elke aand vir die bemanning huisgodsdiens gehou - omdat hulle Christene was en die versoening met God dus 'n belangriks saakl

As versoening dan prakties moet grondvat op Suid-Afrikaanse bodem, wat moet gebeur? Omdat situasies verskil en die konteks van soveel mense wat by versoening so onherhaalbaar anders is, kan definitiewe reëls nie neergelê word nie. Fowler (1993:50-53) stel breë parameters waarbinne versoening behoort te geskied. Hy noem hierdie parameters "acting for reconciliation" en dit kan goedskiks as bloudruk vir enige versoeningspoging en die proses geneem word. Dit behels die volgende elemente:

\section{- Kritiese betrokkenheid}

Kantlynbetrokkenheid is nie goed genoeg nie en Christene wat aktief toetree tot die versoeningsproses sal intens betrokke moet raak. Terselftertyd sal krities gekyk moet word na enige mag/instansie wat die proses wil kelder en dit sal gekonfronteer moet word.

\section{- 'n Allesoorheersende verbondenheid aan geregtigheid}

Dit gaan hier oor die belange van alle mense en die uitwissing van alle mensonterende sake.

\section{- Die beoefening van oop dialoog}

Daar moet na alle partye geluister word, ook dié wat ideologies van jou verskil. Dit beteken dat ' $n$ mens fyn en geduldig luister na wat vir die ander party belangrik is. Dit impliseer ook dat jy jouself oopmaak en 
sonder menslike (gevestigde) verdedigingsmeganismes na jou vyand toe gaan.

\section{- Bemagtigende optrede}

In die proses van versoening moet ander bemagtig ("empower") word om self op te tree en self inisiatief te neem in die samelewing. Dit gaan nie net oor politieke bemagtiging nie, maar ook oor morele en ander soort bemagtiging wat versoening teweegbring. (As Fowler reg verstaan word, impliseer ware versoening dat nuwe bane en geleenthede wat vroeër nie bestaan het nie, vir mense geopen word.)

Die proses van versoening begin telkens by die Christen self en gaan daarvandaan na ander toe as ' $n$ uitnodigende lewenstyl. Uit die Skrif is die beginpunt van enige versoeningsaktiwiteit duidelik: by jouself. Volgens Matteus 18:15 is daar sprake van hierdie proses: "as jou broer verkeerd opgetree het teen jou" (jy het dus ' $n$ probleem met hom) en in Matteus 5:23 "(as) dit jou byval dat jou broer iets teen jou het" (hy het dus ' $n$ probleem met jou) - in albei hierdie gevalle word die gelowige aangemoedig om self die inisiatief te neem en te gaan "vrede maak" (versoen).

Dit word nie met hierdie artikel beoog om 'n volledige program vir versoening daar te stel nie. Daar is egter uiters relevante materiaal wat versoening wel baie duidelik en stapsgewys bespreek. The Peacemaker. A Biblical guide to resolving personal conflict (1991) geskryf deur Ken Sande is 'n standaardwerk, ook vir versoening op regsgebied, en hierdie riglyne word sterk aanbeveel om te implementeer in die proses van versoening.

\section{Die kerk se versoeningsrol in Suid-Afrika}

Die bediening van die kerk van Jesus Christus is dié van "bediening van die versoening" ( 2 Kor. 5:18-20) en daarom behoort die kerk leiding te neem ten opsigte van versoening in die Suid-Afrikaanse samelewing. (Coetzee, 1994:20). Omdat apartheid - wat in 'n groot mate die verwydering van mense in SA teweeggebring het - ' $n$ teologiese fundering gehad het (Cassidy, 1989:117; Gous, 1993:20), behoort die "korreksie" daarop, naamlik versoening, ook teologies gefundeer wees en moet die kerk daarin 'n leidende rol speel. Die kerk (beginnende by die plaaslike kerk) behoort die plek te wees waar versoening begin en verder gevoer word soos Lochman (1979:60) dit treffend stel: "... de gemeente wordt de standplaats der verzoening". Vorster (1996:196) maak ' $n$ belangrike stelling oor die getuienis van die kerk: "Die getuienis van die kerk in die wêreld kan nie anders wees nie as die vertolking van die Woord wat loodreg op mense binne hulle lewenskontekse afkom nie." 
Een van die mees aktuele lewenskontekste waarop die kerk haar behoort te begewe om die Woord vertolkend te laat spreek, is die van versoening. Volgens Schontz en Rosenak (1988:23) is vergewing en gevolglike versoening "... long been held by the church to be a vital part of the emotional, spiritual and even physical healings".

Dit kan nie anders dat die kerk van Jesus Christus sterk leiding neem in die hele saak van versoening nie. Hierdie leiding kan nie alleen wees deur middel van grondige bestudering en akademiese besinning oor wat versoening werklik is en behoort te wees nie (vgl. Lotter, 1996:12-13), maar ook die aktiewe bevordering van versoening tussen mense (Dandala, 1994:11; vgl. ook De Gruchy, 1993:13). Die kerk se profetiese, priesterlike en koninklike taak word uiteindelik uitgevoer wanneer die kerk haar aktief beywer en bemoei met vergewing in die samelewing (Williams, 1992:36). Dit is trouens die kerk alleen wat as agent van die Goddelike versoening kan optree en dit is inderdaad tragies dat die kerk hierdie roeping grootliks nagelaat het. Van Wyk (1991:187) skryf van 'n "houding van kritiese solidariteit" wat die kerk moet hê; 'n gedagte wat 'n mens moontlik soos volg kan parafraseer: volledig deel van en tog getuigend bly teenoor. Wanneer vervolgens uitgespel word hoe sodanige versoeningsaktiwiteite van stapel gestuur word, sal dit die kerk van Jesus Christus wees wat in hierdie opsig die inisiatief moet neem, dit moet begrond en inderdaad aan die gang kry.

\section{Voorgestelde simbole vir versoening}

In 1986 maak Dirkie Smit die volgende stelling: "At the present stage of the ideological struggle in South Africa, the symbol of reconciliation does not seem (to me) to have the necessary symbolic power to transform the society" (Smit, 1986:85). Dit was waarskynlik 'n geldige en gepaste stelling in die tyd van die hoogbloei van die struggle (vgl. Cassidy, 1989:116) aan die een kant en die optrede van die regering aan die ander kant. Suid-Afrika was inderdaad 'n gepolariseerde land (vgl. Van Wyk, 1991:173, 174). Vanweë baie dinge wat gebeur het, byvoorbeeld die skuldbelydenisse van verskillende kerke oor apartheid, die werk van die Waarheids-en Versoeningskommissie, veranderde gesindhede wat op verskillende vlakke van die samelewing ontwikkel het en ' $n$ menigerlei ander redes, is die tyd nou ryp vir (nuwe) versoeningsimbole. Hierdie simbole sal nie deur die regering "gebou" kan word nie, maar deur die inisiatief van die kerke omdat die ware boodskap van versoening daarvandaan na vore behoort te kom. Volgens Tutu (1999:60) moet hierdie simbole ("monuments and memorials") so inklusief moontlik wees en dit impliseer verder dat Suid-Afrikaners selfs sal leer om fees te vier by geleenthede van historiese belang soos die inhuldiging van die 
president van die land of by nasionale oorwinnings met sportgeleenthede.

Die kerke sal op grondvlak en op organiese wyse aan hierdie saak aandag moet gee sonder dat dit verpolitiseer word. Verpolitisering sal in elk geval weer 'n aantal mense vervreem en sodoende juis die saak van versoening kelder.

Watter soort simbole sal dan moontlik wees? In terugblyk blyk dit dat die twee mees nasionale simbole van die nuwe Suid-Afrika, naamlik die vlag en die volkslied, goed ontvang is en deur die grootste meerderheid van die bevolking hulle eie gemaak is. Nuwe voorgestelde simbole sal so ontwerp moet word dat dit nie aanstoot gee nie, en tog die emosionele impak sal hê wat normaalweg met simbole uitgedruk wil en behoort te word. Ironies genoeg noem Van Houten (1998:4) as buitelander die moontlikheid om baie meer van Versoeningsdag (16 Desember) te maak, terwyl Tutu (1999:63) ook daarvan melding maak. Sal dit nie 'n besondere teken van versoening wees as Christelike kerke van verskillende kultuurgroepe op daardie dag bymekaar kom om in die eerste plek die versoening wat reeds in Christus bestaan, uit te druk nie! SACC (2000:3) formuleer dit só:

The Church should rehabilitate the observance of December 16 (Day of Reconciliation) in order to facilitate national confession, healing and reconciliation as necessary for our fledging democracy.

Moet die fokus nie eerder op die toekoms gerig word by Christelike byeenkomste van daardie dag, in plaas van om slegs by die verlede stil te staan nie? Daar is dus aireeds ' $n$ dag wat besondere ruimte bied vir al die bevolkingsgroepe in Suid-Afrika om die versoening op 'n besondere wyse te vier. Die kerk behoort getuigend-kreatief te werk gaan om hierdie reeds bestaande middel te gebruik. Omdat die dag egter die aanbreek van die Desembervakansie inlui, is dit dikwels moeilik om groot "volksfeeste" op daardie dag te hou.

Ander moontlikhede kan die volgende wees:

- Christelike kerke kan byvoorbeeld doelbewus en gereeld versoeningsdienste hou saam met ander kultuurgroepe wat dalk selfs vroeër vyandig teenoor mekaar gestaan het. Voorbeelde bestaan reeds van multikulturele gemeentes wat saam Pinksterdienste hou en daar kan op daardie basis verder gebou word.

- Verskillende kuns- en grafiese vorme kan byvoorbeeld gebruik word om versoening uit te beeld. In die tyd van die struggle is musiek en grafiese voorstellings soms gebruik om 'n boodskap oor te dra (vgl. 
Villa-Vicencio, 1999:54). So ook het talle Suid-Afrikaanse uitgewekenes in die jare van die struggle kunsuitstallings gehou waar die vryheidstryd op aanskoulike wyse uitgebeeld is. Vandag kan byvoorbeeld gebruik gemaak word van muurpanele en voorstellings van versoeningstonele op groot advertensieborde langs hoofpaaie in ons land.

- Om iets tasbaars (soos 'n monument) te bou wat iets van die versoening konkreet uitdruk. So 'n monument kan op 'n plek gebou word wat besondere emosionele konnotasies in die Suid-Afrikaanse geskiedenis na vore roep, soos byvoorbeeld die World Trade Centre in Kemptonpark waar die Codesa-berade gehou is.

- Leerders in skole kan een dag afsonder en op verskillende kreatiewe wyses meewerk aan die konsep van versoening (vgl. Summers, 1992:30). Die moontlikhede is legio. Leerders kan byvoorbeeld tekeninge maak van hoe hulle versoening begryp. Ook kan skoolbesoeke aan versoeningsmonumente gereël word om by die leerders die idee van versoening ook op konkrete wyse in te skerp.

- 'n Boek van "versoeningsverhale" kan gepubliseer word as gesamentlike aksie van verskillende kultuurgroepe en mense wat vroeër juis vyandig was. Aangrypende verhale (ook van versoening) het ontvou na 1994 (vgl. Tutu, 1999:82, 115; Meiring, 1999:72).

So sal ander moontlikhede sekerlik ook bedink en uitgevoer kan word moontlikhede wat deur gemeenskappe self geïnisieer kan word in die skep van versoeningsimbole.

\section{Gevolgtrekking}

Dit blyk dat daar steeds (en dit sal waarskynlik altyd so bly) ' $n$ behoefte sal wees aan ware Bybelse versoening as 'n deurwerk en ' $n$ uitwerk na ander mense toe van die Goddelike versoening wat in Jesus Christus volledig eens en vir altyd plaasgevind het. Dit is verder duidelik dat daar kardinale dimensies in die proses van versoening is wat nie agterweë gelaat kan word nie, soos vergewing as voorwaarde en restitusie as gevolg van versoening. Die agent wat hierdie belangrike proses aan die gang moet kry omdat sy uitnemend daarvoor toegerus is, is die kerk van Jesus Christus en dit kan suksesvol gedoen word met die daarstelling van nuwe simbole van versoening waarvoor die tyd nou ryp is in SuidAfrika. 


\section{Bibliografie}

BRÜMMER, V. 1994. Kairos, reconciliation and the doctrine of atonement. Journal of Theology for Southern Africa, 88:42-58, Sept

CASSIDY, M. 1989. The passing summer. A South African pilgrimage in the politics of love. London: Hodder \& Stoughton

CLOETE, G.D. \& SMIT, D.J. 1984. 'n Oomblik van waarheid. Opstelle van die NG Sendingkerk se afkondiging van 'n status confessionis en die opstel van 'n konsepbelydenis. Kaapstad : Tafelberg.

COETZEE, C. 1994. The real challenge to the church. Woord en Daad, 34(347):1820, Herfs.

DANDALA, M. 1994. A perspective on mission and peacemaking Missionalia, 22(1):5-12, Apr.

DE GRUCHY, J.W. 1993. National reconstruction. Journal of Theology for Southern Africa, 83:5-13.

DE KLERK, B.J. 1999. Skuldbelydenis en versoening as kommunikatiewe handeling in die liturgie van die samekoms en van die lewe. Praktiese Teologie, 14(2):2345

DU TOIT, Z.B. 1999. WWK-verslag vertel nie die volle waarheid nie en is erg gebrekkig: versoening nie hiermee moontlik. Rapport. 7, Aug. 1.

FOWLER, S. 1993. Reconciliation in a heterogeneous society. Potchefstroom : PU vir $\mathrm{CHO}$. (Wetenskaplike bydraes van die PU vir $\mathrm{CHO}$. Reeks F1, no. 306. Jun.)

GOUS, G. 1993. From the church struggle to a struggling church: a tale of three conferences: Cottesloe, Rustenburg and Cape Town. Missionalia, 21(3):253-271, Nov.

GUNTON, C.E. 1989. The actuality of atonement. A study of metaphor, rationality and the Christian tradition. Grand Rapids, Mi. : Eerdmans.

HELBERG, J.L. 1990. Die verbondsvolk se verhouding tot sy land. Potchefstroom : PU vir $\mathrm{CHO}$ (Wetenskaplike bydraes. Reeks $\mathrm{A}$, no. 76. )

HOFMEYR, J.W. 1992. Die einde van die ou Suid-Afrika, die begin van die nuwe Suid-Afrika: die rol van die kerk in kritiese oorgangsjare. (In Meiring, P.G.J. \& Joubert, S.J., reds. Fokus op die kerk. Die rol van die kerk in 'n veranderende Suid-Afrika. Vereeniging : Christelike Uitgewersmaatskappy. p. 96-111.)

KAIROS DOCUMENT. 1985. The challenge to the church. A theological comment on the political crisis in South Africa. Braamfontein : The Kairos Theologians.

KÖNIG, A. 1995. Versoening: goedkoop? Duur? Verniet? Kaapstad : Lux Verbi

KRISHNA, P. 1993. Reconciliation in tribalist/racist societies. Potchefstroom : PU vir CHO. (Wetenskaplike bydraes van die PU vir CHO. Reeks F1, no. 306.)

KROG, A. 1998. Country of my skull. Johannesburg : Random House.

KRÜGER, P.P. 1999. Die gereformeerde konvent - 'n belowende begin. Woord en Daad, 369:23-24

LOCHMAN, J.M. 1979. Verzoening en bevrijding. Een nieuwe bezinning op het heil. Baarn: Oekumene.

LOTTER, G.A 1987. Counseling divorcees on forgiveness. Philadelphia Westminster Theological Seminary. (D.Min. Thesis.)

LOTTER, G.A. 1996. Forgiveness in post-apartheid South Africa. Acta Theologica, 16(2):120-128. Dec

LOTTER, G.A. 1999. Reconciled people are more healthy: a South African view on human rights abuses, truth and reconciliation. Second South African Congress on Christian Counseling. Ongepubliseerde lesing

LOUW, D.J. 1996. Guilt and change - the healing power of forgiveness. Scriptura, 59(4): 383-395 
LOUW, J.P. \& NIDA, E.A. 1988. Greek-English Lexicon. Vol. 1 \& 2. New York: United Bible Societies.

MASWANGANYI, E. 1992. The role of the church in helping to shape a new South Africa. Potchefstroom : PU vir $\mathrm{CHO}$ (Wetenskaplike bydraes van die PU vir $\mathrm{CHO}$, Reeks F1, no. 292)

MEIRING, P. 1999. Kroniek van die waarheidskommissie. Op reis deur die verlede en hede na die toekoms van Suid-Afrika. Vanderbijlpark : Carpe Diem

MULLER, J.C. 1996. Political violence in South Africa as a communicative action: A pastoral-systemic view. Scriptura, 59(4):413-420

POTGIETER, P. 1991. Understanding the church situation and obstacles to Christian witness in South Africa. (In Alberts, L. \& Chikane, F., eds. The road to Rustenburg. The church looking forward to a new South Africa. p. 100.)

RABALI, C. 1987. Another response to the Kairos Document. (In'n Reformatoriese kommentaar op die Kairos-dokument. Potchefstroom: IRS. Reeks F1, no. 231, 232.)

SACC. 2000. "The reconciliation process has barely begun". Resolutions endorsed by the 1998 National Conference. (/n SACC News Page op http://ww. sacc.org.za/news.html onttrek op 03/14/2000.)

SANDE, K. 1991. The peacemaker. A biblical guide to resolving personal conflict. Grand Rapids, Mi. : Baker Book House.

SCHONTZ, F.C. \& ROSENAK, C. 1988. Psychological theories and the need for forgiveness: assessment and critique. Joumal of Psychology and Christianity, $7(1): 23-31$

SMIT, D. 1986. The symbol of reconciliation and ideological conflict in South Africa. (In Vorster, W.S., ed. Reconciliation and construction: Creative options for a rapidly changing South Africa. Pretoria : Unisa [Miscellanea Congregalia 27]. p. 79-112.)

SMIT, D. 1996. Oor die kerk as 'n unieke samelewingsverband. Tydskrif vir Geesteswetenskappe, 36(2):119-129, Jun.

SMIT, K. 1992. Swart perspektiewe op affirmative action. Koers, 57(1):31-57, Mrt

SUMMERS, H.C. 1992. Education for reconciliation. Scriptura, 43:21-33, Sept.

TRUTH \& RECONCILIAN COMMISSION/REPORT. 1998. Cape Town : CTP Book Printers. (5 vols.)

TURAKI, Y. 1993. Human dignity and identity; according to apartheid and according to the Word of God. Potchefstroom : PU vir $\mathrm{CHO}$. (Wetenskaplike bydraes van die PU vir CHO. Reeks F no. 302).

TUTU, D. 1999. No future without forgiveness. London : Rider.

VAN DER WALT, B.J. 1999. Kerkvernuwing onderweg na 2000. Visie - Missie Konteks. Potchefstroom: Wetenskaplike bydraes van die PU vir $\mathrm{CHO}$. (Reeks F1, no. 379.)

VAN HOUTEN, R.L. 1998. Reconciliation and forgiveness. Mission Bulletin, 18(2):319, Dec.

VAN ROOY, J.A. 1999. The Christian gospel as a basis for escape from poverty in Africa. In die Skriflig, 33(2)235-253, Jun.

VAN WYK, J.H. 1991. Kerklike getuienis in 'n polities gepolariseerde Suid-Afrika. (In Helberg, J.L., red. Kerkwees as getuienis. Potchefstroom : PTP. p. 127-139.)

VAN WYK, J.H. 1999. Skuldbelydenis in teologiese perspektief. In die Skriflig, 33(2):203-224, Jun.

VENTER, C J.H 1991. Versoening en die prediking van versoening vandag. (In Helberg, J.L., red. Kerkwees as getuienis in Suid-Afrika vandag. Potchefstroom : PTP. p. 213-224.) 
VILLA-VICENCIO, C. 1999 Now that the TRC is over. Looking back, reaching forward. Journal of Theology for Southern Africa, 18(1):43-56, Nov.

VORSTER, J.M. 1996. Is die kerk funksioneel? Gedagtes oor Gereformeerde kerkvernuwing in 'n postmoderne konteks. Potchefstroom: Potchefstroomse Teologiese Publikasies.

WALKER, D.S. 1994. Evangelicals and apartheid revisited. Journal of Theology for Southern Africa, 89:42-50, Dec.

WILLIAMS, D.T. 1992. Reconciliation: God, humanity, society: a Christian approach Theologia Evangelica. 25(3):32-43, Sept.

\section{Kernbegrippe:}

kerk

restitusie

simbole

vergewing

versoening

Key concepts:

church

forgiveness

reconciliation

restitution

symbols 